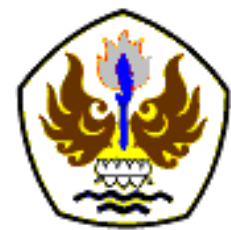

INFOMATEK

Volume 22 Nomor 1 Juni 2020

\title{
RANCANG BANGUN MESIN CNC ROUTER PORTABLE DENGAN DIMENSI 1219×609 MM UNTUK SKALA LABORATORIUM
}

\author{
Bambang Setiawan ${ }^{*}$, Rasma, Thomas Djunaedi \\ Program Studi Teknik Mesin \\ Universitas Muhammadiyah Jakarta
}

\begin{abstract}
Abstrak: Karya ukir kayu memiliki kekhasan tersendiri karena merupakan suatu karya cipta manusia yang didasari rasa estetis sesuai apa yang diinginkan oleh manusia itu sendiri. Karya seni ukir kayu biasanya diciptakan menggunakan teknik memahat. Dengan menggunakan teknik memahat membuat hasil produksi per harinya mendapatkan hasil yang sedikit dan dengan kualitas produk yang tidak seragam. Sehingga dibutuhkan penggunaan mesin $\mathrm{CNC}$ router, agar dapat meningkatkan hasil yang memuaskan serta jumlah produk yang banyak. Namun pada umumnya mesin CNC pada umumnya CNC Router pada pasaran masih menggunakan poros ulir sebagai transmisi geraknya dan dengan daya motor yang besar. Maka dari itu transmisi gaya penulis menggunakan ballscrew. Ballscrew dipilih karena pada ballscrew tidak terjadi keterlambatan gerak balik atau biasa disebut backlash. Karena apabila terjadinya backlash dapat menyebabkan ketepatan nilai akurasi dan kalibrasi berkurang. Serta penggunaan motor stepper dengan daya sebesar 0.9478 watt, dengan kecepatan motor spindle minimal adalah $15000 \mathrm{rpm}$, dengan maks diameter tool $6 \mathrm{~mm}$, didapatkan torsi $6.912 \mathrm{~N} . \mathrm{m}$ dengan daya motor maks yaitu $0.1086 \mathrm{Kw}$. Kemudian dari pada itu untuk panjang gerak area kerja mesin CNC Router ialah pada sumbu X adalah $286 \mathrm{~mm}$, pada sumbu $Y$ sebesar $426 \mathrm{~mm}$ dan pada sumbu $Z$ sebesar $31 \mathrm{~mm}$.
\end{abstract}

Kata kunci: CNC, Engraving, router, Ukir kayu, bearing rail assembly

\section{PENDAHULUAN}

Karya ukir kayu memiliki kekhasan tersendiri karena merupakan suatu karya cipta manusia yang didasari rasa estetis sesuai apa yang diinginkan oleh manusia itu sendiri. Karya seni ukir kayu biasanya diciptakan menggunakan teknik memahat (https://www.medaNCNC.com [1]). Penciptaan karya-karya kerajinan ukir kayu diawali dengan proses merancang pola/ bentuk yang akan diterapkan pada ukir kayu

\footnotetext{
*) bambang.setiawan@ftumj.ac.id
}

Pertama diterima: 21 Mei 2020

Direvisi:26 Mei 2020

Disetujui untuk publikasi: 29 Mei 2020 dengan menggunakan keterampilan memahat yang kreatif demi menghasilkan karya yang baik, menarik, serta memiliki makna dan nilai estetika yang tinggi.

Namun dalam perkembangannya pengrajin seni ukir kayu mulai jarang dan banyak beralih profesi lain karena mengukir membutuhkan waktu yang relatif lama dan membutuhkan keterampilan khusus. Oleh sebab itu, perlu adanya suatu terobosan untuk mempermudah dan memperingkas hasil pekerjaan tersebut, salah satu cara inovasi tersebut ialah dengan 
memungkinkan penggunaan mesin $\mathrm{CNC}$ (computer numerical control) (https://id.wikipedia.org/wiki/CNC [2]). Ini adalah hasil dari perbaikan yang revolusioner dan inovasi dalam metode ukiran kayu menggunakan mesin yang dikendalikan komputer yang dikenal sebagai router $C N C$ (https://www.medaNCNC.com/single-

post/jasa-potong-CNC-router [3]), (Saputra dkk [4]), (Sashank [5]).

Berdasarkan literatur dan data, maka perencanaan ini dilakukan, yaitu merancang bangun sebuah mesin $C N C$ dengan biaya yang rendah dengan mengganti meja mesin ataupun kerangka mesin yang biasanya menggunakan bahan besi ataupun alumunim profil. Dengan memanfaatkan kayu MDF sebagai frame atau kerangka mesin dan adapun bed mesin/ meja mesin pun menggunakan kayu MDF sebagai pengganti pengunaan besi. Peneliti merancang bangun suatu mesin CNC (computer numerical control) yang dapat digunakan untuk memproses engraving atau dengan istilah lain yaitu menggambar suatu pola pada bidang tertentu secara otomatis.

Dengan adanya penggunaan mesin $\mathrm{CNC}$ tersebut pengrajin dapat memaksimalkan pesanan yang seragam walaupun dengan jumlah yang banyak sekalipun.

\section{METODOLOGI}

\subsection{Tahapan Perancangan}

Dalam perancangan mesin router portable ini pengoperasian menggunakan software mach 3 ini yang harus dilakukan agar perancangan dapat berjalan lancar yakni melakukan survei kebutuhan. Survei ini dilakukan dengan tujuan mendapatkan gambaran tentang desain dan sistem kerja mesin CNC yang sesuai dengan keinginan. Adapun diagram alir perancangan ditunjukkan seperti Gambar 1.

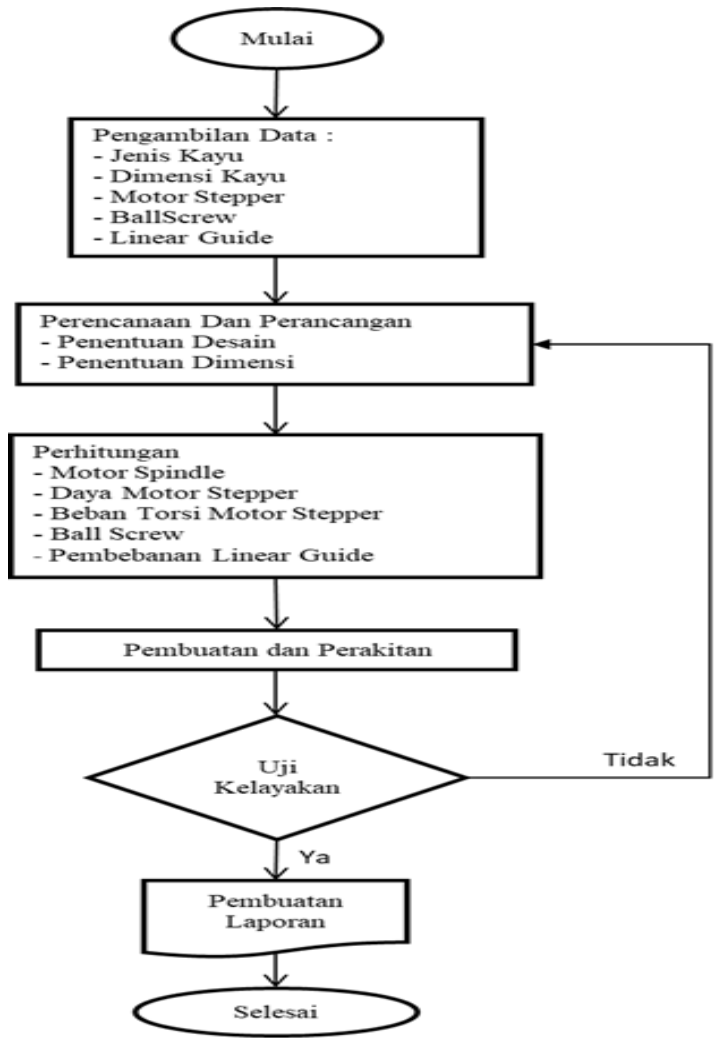

Gambar 1. Diagram Alir Perancangan

\subsection{Pengambilan Data}

Dalam merencanakan pembuatan mesin CNC router portable ini terlebih dahulu dilakukan 
pengamatan dan pengujian secara langsung sehingga dapat mempertegas penulisan. Perancangan dan pembuatan mesin CNC Router portable dikerjakan dengan melakukan pengamatan secara langsung pada mesin CNC Router.

\subsection{Tempat dan Waktu}

Pelaksanaan, pembuatan, dan pengujian mesin CNC router sederhana ini dilakukan di workshop dan di Citra Lab Bekasi. Analisa, perancangan, pembuatan dan pengujian alat dilaksanakan selama \pm 3 bulan berdasarkan pada jadwal yang ditentukan.

\subsection{Alat dan Bahan}

\subsubsection{Alat}

Dalam perancangan ini, alat yang digunakan adalah sebagai berikut:

1. CNC Router sederhana

2. Vernier caliper

3. Roughness tester

4. Mistar

5. Tachometer

6. Water pass

Gambar 2 (a), (b) dan (c) memperlihatkan alatalat yang digunakan tersebut.

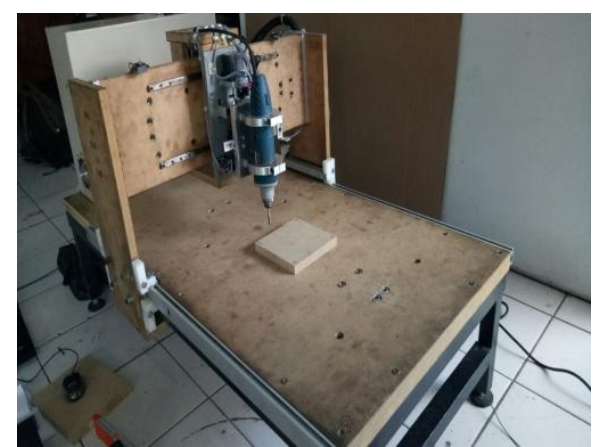

(a)

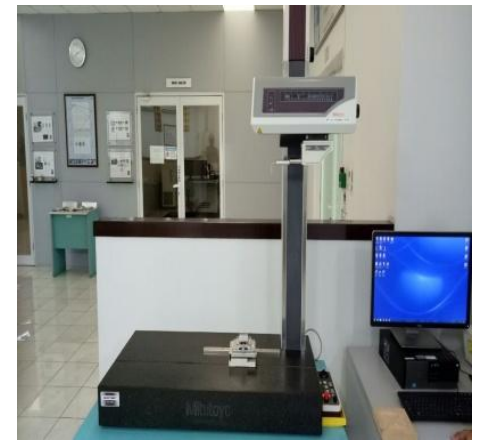

(b)

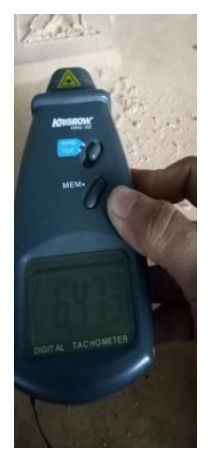

(c)

Gambar.2

Alat Yang Digunakan (a) CNC Router (b) Roughness Tester (C) Tachometer

\subsubsection{Bahan}

Bahan yang digunakan dalam pengujian ini menggunakan kayu MDF dengan tebal 18 $\mathrm{mm}$. 


\section{ANALISIS DAN PEMBAHASAN}

\subsection{Perhitungan Perancangan Alat}

Perancangan alat yang dilakukan yaitu pada spindle motor. Spindle motor adalah motor yang berfungsi untuk menggerakan cutting tools/ alat potong. Torsi dan rpm yang sangat mempengaruhi kebutuhan pergerakan pemakanan. Diasumsikan gaya pemakanan adalah $22 \mathrm{~N}$.

$$
\begin{aligned}
\text { Fs } & =0,8 \cdot u \cdot t \cdot \sigma t \\
& =0,8 \cdot 780 \cdot 30 \cdot 12 \\
& =224640 \mathrm{~N} \cdot \mathrm{mm}=22 \mathrm{~N} \cdot \mathrm{m}
\end{aligned}
$$

Dimana : Fs : gaya pemakanan $(\mathrm{N})$ dan diameter cutting tool adalah $6 \mathrm{~mm}(r=0.003$ $\mathrm{m})$.

$$
\begin{aligned}
\mathrm{T} & =\mathrm{Fs} \times \mathrm{r} \\
& =224640 \times 0.003 \\
& =673,92 \mathrm{~N} . \mathrm{m}
\end{aligned}
$$

Daya maksimum rpm yang direncanakan pada motor spindle adalah 18.000 rpm, maka didapat maksimum daya untuk motor spindle:

$$
\begin{aligned}
P & =T \times \frac{2 \pi \cdot n}{60} \\
& =673,92 \times \frac{2 \pi .18000}{60} \\
& =673,92 \times 1884,96 \\
& =1270312,24 \mathrm{~W} \\
& =1270,31 \mathrm{~kW}
\end{aligned}
$$

Untuk merancang mesin CNC router portable ini perlu adanya perencanaan daya motor yang diperlukan agar sesui dengan kebutuhan. Perencanaan yang diinginkan adalah dengan motor stepper 200 pulsa/rotasi dan kecepatan pulsa masuk 1000 pulsa/detik, maka dapat direncanakan kecepatan putar motor $n$.

$$
\begin{aligned}
& n=60 \frac{P p s}{N p} \\
& n=60 \frac{1000}{200} \\
& \mathrm{n}=300 \mathrm{Rpm}
\end{aligned}
$$

1. Perencanaan Daya Motor pada Sumbu X Torsi yang dibutuhkan motor untuk menggerakkan sumbu $X$ yaitu :

$$
\begin{aligned}
\mathrm{F}= & \mathrm{m} \cdot \mathrm{g} \\
\mathrm{F}= & 0,562 \mathrm{~kg} \cdot 9 \cdot 8 \mathrm{~m} / \mathrm{s}^{2} \\
\mathrm{~F}= & 5,5076 \mathrm{~kg} \cdot \mathrm{m} / \mathrm{s} 2(\mathrm{~N}) \\
\mathrm{F}= & \text { Gaya yang direncanakan pada sumbu } \\
& \mathrm{X}(\mathrm{N}) \\
\mathrm{T}= & \mathrm{F} \cdot \mathrm{r} \\
\mathrm{T}= & 5,5076 \mathrm{~N} \cdot 0,008 \mathrm{~m} \\
\mathrm{~T}= & 0,0440608 \mathrm{~N} \cdot \mathrm{m} \\
\mathrm{T}= & \text { Torsi yang direncanakan pada motor } \\
& (\mathrm{N} \cdot \mathrm{m}) \\
\mathrm{r}= & \text { Jari-jari poros penggerak yaitu } 8 \mathrm{~mm}= \\
& 0,008 \text { (m) }
\end{aligned}
$$

Sedangkan untuk daya yang dibutuhkan pada motor stepper dapat diketahui dengan menghitung kecepatan sudut $(\omega)$ terlebih dahulu,

$\omega=\frac{2 \pi n}{60}$ 
$\omega=\frac{2 \pi 300}{60}$

$\omega=31,4 \mathrm{rad} /$ detik

Sehingga dapat ditentukan daya motor

yang dibutuhkan pada sumbu $X$ :

$\mathrm{P}=\mathrm{T}$. $\omega$

$P=0,0440608$ N.m . 31,4 rad $/$ detik

$P=0,13835$ watt

Untuk beban torsi yang harus ditopang motor stepper sumbu $X$ adalah 0,02968 N.m Jadi motor stepper sumbu $X$ dinyatakan Aman $0,0440608 \mathrm{Nm}<6,8 \mathrm{Nm}$.

\section{Perencanaan Daya Motor pada Sumbu $Y$}

Torsi yang dibutuhkan motor untuk menggerakkan sumbu $Y$ yaitu:

$$
\begin{aligned}
\mathrm{F}= & \mathrm{m} \cdot \mathrm{g} \\
\mathrm{F}= & 0,770 \mathrm{~kg} \cdot 9 \cdot 8 \mathrm{~m} / \mathrm{s} 2 \\
\mathrm{~F}= & 7,546 \mathrm{~kg} \cdot \mathrm{m} / \mathrm{s} 2(\mathrm{~N}) \\
\mathrm{F}= & \text { Gaya yang direncanakan pada sumbu } \\
& \quad \mathrm{X}(\mathrm{N}) \\
\mathrm{T}= & \mathrm{F} \cdot \mathrm{r} \\
\mathrm{T}= & 7,546 \mathrm{~N} \cdot 0,014 \mathrm{~m} \\
\mathrm{~T}= & 0,08134 \mathrm{~N} \cdot \mathrm{m} \\
\mathrm{T}= & \text { Torsi yang direncanakan pada motor } \\
& \quad(\mathrm{N} \cdot \mathrm{m}) \\
\mathrm{r}= & \text { Jari-jari poros penggerak yaitu } 14 \mathrm{~mm} \\
= & 0,014(\mathrm{~m})
\end{aligned}
$$

Sedangkan untuk daya yang dibutuhkan pada motor stepper dapat diketahui dengan menghitung kecepatan sudut $(\omega)$ terlebih dahulu.

$\omega=\frac{2 \pi n}{60}$

$\omega=\frac{2 \pi 300}{60}$

$\omega=31,4 \mathrm{rad} /$ detik

Sehingga dapat ditentukan daya motor yang dibutuhkan pada sumbu $X$ :

$\mathrm{P}=\mathrm{T}$. $\omega$

$P=0,08134$ N.m . 31,4 rad $/$ detik

$P=2,554$ watt

Untuk beban torsi yang harus ditopang motor stepper sumbu $Y$ adalah 0,02884 N.m Jadi motor stepper sumbu $\mathrm{X}$ dinyatakan Aman $0,08134 \mathrm{Nm}<6,8 \mathrm{Nm}$.

3. Perencanaan Daya Motor pada Sumbu Z Torsi yang dibutuhkan motor untuk menggerakkan sumbu $X$ yaitu:

$\mathrm{F}=\mathrm{m} \cdot \mathrm{g}$

$\mathrm{F}=0,157 \mathrm{~kg} \cdot 9.8 \mathrm{~m} / \mathrm{s} 2$

$\mathrm{F}=1,53 \mathrm{~kg} \cdot \mathrm{m} / \mathrm{s} 2(\mathrm{~N})$

$\mathrm{F}=$ Gaya yang direncanakan pada sumbu $\mathrm{X}(\mathrm{N})$

$\mathrm{T}=\mathrm{F} \cdot \mathrm{r}$

$\mathrm{T}=1,53 \mathrm{~N} \cdot 0,008 \mathrm{~m}$

$\mathrm{T}=0,01224 \mathrm{~N} . \mathrm{m}$

$\mathrm{T}=$ Torsi yang direncanakan pada motor (N.m)

$r=$ Jari-jari poros penggerak yaitu $8 \mathrm{~mm}$ $=0,008(\mathrm{~m})$ 
Sedangkan untuk daya yang dibutuhkan pada motor stepper dapat diketahui dengan menghitung kecepatan sudut $(\omega)$ terlebih dahulu.

$\omega=\frac{2 \pi n}{60}$

$\omega=\frac{2 \pi 300}{60}$

$\omega=31,4 \mathrm{rad} /$ detik

Sehingga dapat ditentukan daya motor yang dibutuhkan pada sumbu $Z$ :

$\mathrm{P}=\mathrm{T} . \omega$

$\mathrm{P}=0,01224 \mathrm{~N} \cdot \mathrm{m} .31,4 \mathrm{rad} /$ detik

$P=0,384336$ watt

Untuk beban torsi yang harus ditopang motor stepper sumbu Z adalah 0,0104 N.m Jadi motor stepper sumbu $X$ dinyatakan Aman $0,0104 \mathrm{Nm}<3 \mathrm{Nm}$. Sedangkan untuk daya yang dibutuhkan pada motor stepper adalah

\section{0,384336 watt.}

Berdasarkan data yang didapat dari perhitungan torsi terbesar dan daya terbesar ditentukan motor stepper dengan daya dan torsi yang lebih besar yaitu $\mathrm{P}=20,4$ watt, $\mathrm{T}=$ $4 \mathrm{Kg} \cdot \mathrm{Cm}=0,04 \mathrm{Kg} \cdot \mathrm{m}=3,92 \times 10-1 \mathrm{~N} \cdot \mathrm{m}$. Dipilihnya motor stepper karena harga yang relatif lebih murah dibanding dengan motor servo.

\subsection{Uji Kelayakan Mesin}

Untuk mengetahui besarnya penyimpangan terhadap ketelitian perlu dilakukan pengujian. Pengujian awal yang harus dilakukan yaitu pengujian geometrik secara statik, yaitu pengukuran ketelitian geometri suatu mesin yang dilakukan dalam keadaan diam (tak bekerja) dan tak dibebani (Bagiasna [6]). Pengukuran dilakukan terhadap dimensi geometri berbagai elemen perkakas dan hubungan gerak relatifnya satu terhadap yang lain, seperti kelurusan gerakan carriage carriage terhadap spindle head dan lain-lain. Uji kelayakan mesin meliputi:

\section{Ketegak Lurusan (squarness)}

Ketegak lurusan pada mesin perkakas pada umumnya menyangkut garis, sumbu maupun bidang dan ketegak lurusan gerak komponen. Dua buah bidang atau dua garis lurus atau suatu garis lurus dan sebuah bidang dinyatakan tegak lurus satu terhadap lainnya apabila penyimpangannya terhadap sebuah harga tegak lurus baku tidak melapaui suatu harga batas tertentu. Pada kenyataannya untuk pengukuran besarnya penyimpangan sering digunakan jam ukur (dial indicator),sedangkan sebagai alat bantunya digunakan penyiku atau test bar siku. 


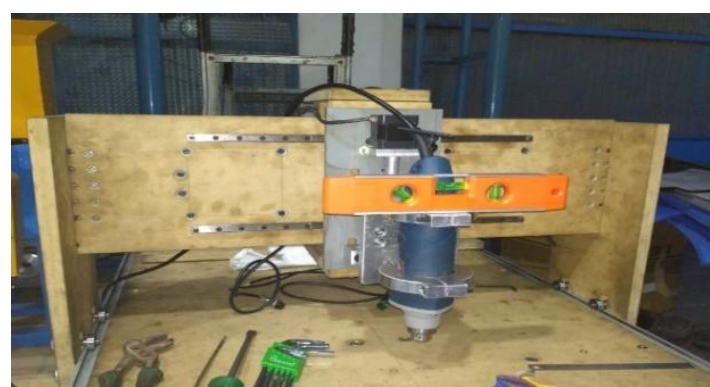

Gambar 3.

Mengecek Ketagak Lurusan Spindle

\section{Kesejajaran (parallelsm)}

Dalam mesin perkakas terdapat bidang, bagian permukaan, garis ataupun gerakan komponen yang dalam interaksinya harus sejajar satu dengan lainnya sedemikian rupa sehingga ketelitian bentuk maupun geometric benda kerja yang di hasilkannya masih berada dalam batas toleransi yang direncanakan.

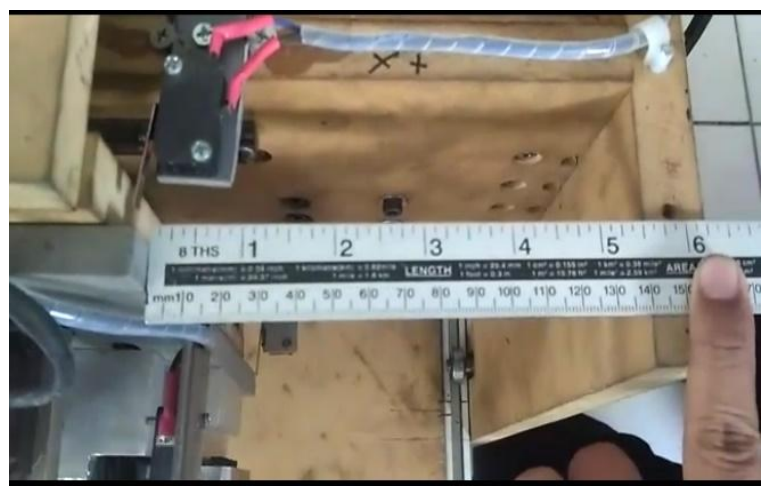

Gambar 4.

Mengecek Kesejajaran Untuk Menghasilkan Nilai Ketelitian Motor

\section{Kerataan (flatness)}

Suatu bidang permukaan dinyatakan bila perubahan jarak tegak lurus dari titik-titik pada permukaan itu terhadap bidang geometric yang sejajar dengan permukaan yang diuji adalah lebih kecil dari suatu harga batas yang tertentu. dalam pengujian ketelitian geometrik mesin perkakas maka bidang geometrik yang dimaksud diatas adalah merupakan bidang referensi.

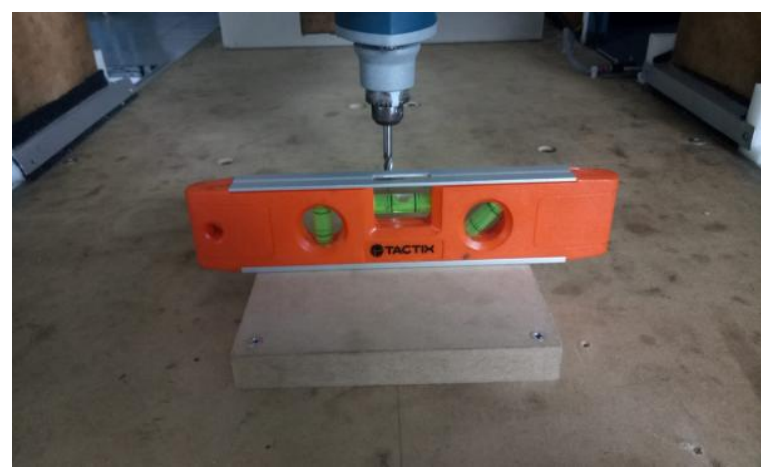

Gambar 5

. Kerataan Meja Pada Benda Kerja

\subsection{Penyempurnaan Alat}

Penyempurnaan alat ini dilakukan apabila terhadap pengujian terdapat masalah atau kekurangan sehingga tidak berfungsi dengan baik sesuai prosedur tujuan dan perancangan yang dilakukan.

\section{IV.KESIMPULAN}

Berdasarkan hasil design dan perencanaan mesin CNC Router Portable dapat diambil kesimpulan sebagai berikut: 
1. Desain CNC Router Portable menggunakan model mesin moving gantry, dengan tipe motor spindle menggunakan mini grinder, lalu untuk sistem transmisinya menggunakan ballscrew adapun untuk bantalan geraknya menggunakan bearing berporos atau linear motion guide.

2. Torsi pada mini grinder dan daya yang direncankan yaitu $\mathrm{T}=6.912 \times 10^{-7} \mathrm{~N}$. m dengan daya motor maks $\mathrm{P}=0.1086 \mathrm{~kW}$.

3. Daya yang diperlukan pada motor stepper sumbu $X$ ialah 0.6908 watt dengan voltage sebesar 4.2 V. Sedangkan pada motor stepper sumbu $\mathrm{Y}$ adalah 0.9478 watt dengan voltage sebesar $4.2 \mathrm{~V}$. Kemudian untuk motor stepper sumbu Z ialah 0.76616 watt dengan voltage sebesar 8.4 $\mathrm{V}$.

4. Lalu dengan diameter ball screw $0,008 \mathrm{~m}$ dan pitch $0.002 \mathrm{~m}$ mempunyai torsi yang digunakan untuk menggerakan ballscrew $\mathrm{X}$ dan Z adalah 0.018972 N.m sedangkan ballscrew $Y$ dengan diameter ballscrew $0.016 \mathrm{~m}$ dan pitch gang ballscrew $0.005 \mathrm{~m}$ mempunyai torsi untuk menggerakan ballscrew $Y$ sebesar $0.052632 \mathrm{Nm}$

5. Dengan berat yang telah sudah direncanakan didapatkan nilai gaya gesek sumbu $X$ pada ballscrew ialah $28.55 \mathrm{~N}$. Kemudian ballscrew gesek sumbu $Y$ adalah $81.76 \mathrm{~N}$. Dan untuk sumbu $Z$ gaya geseknya pada ballscrew ialah $24.25 \mathrm{~N}$.
6. Untuk hasil perhitungan pembebanan Linear Motion Guide pada sumbu X, Y dan $Z$ pada sumbu $X$ ialah $22.25 \mathrm{~N}$. Kemudian untuk sumbu $Y$ total pembebanan nya ialah 78.4 N. Sedangkan pada sumbu Z mempunyai total pembebanan sebesar $23.53 \mathrm{~N}$.

\section{DAFTAR PUSTAKA}

[1] Medan CNC, 3 Fungsi Utama CNC Router, https://www.medaNCNC.com/singlepost/jasa-potong-CNC-router, diakses Mei 2020

[2] CNC, https://id.wikipedia.org/wiki/CNC, diakses Mei 2020

[3] Medan CNC, 3 Fungsi Utama CNC Router, https://www.medaNCNC.com/singlepost/jasa-potong-CNC-router, diakses Mei 2020

[4] Saputra, R. P. dkk, Desain dan Implementasi Sistem Kendali CNC Router Menggunakan PC Untuk Flame Cutting Machine, Universitas Gadjah Mada, Yogyakarta, 2011

[5] Sashank, T. Structural Design Of 3 Axis CNC Machine Tool For Wood Carving, Patiala, 2014.

[6] Bagiasna, K. Pengetesan Kondisi dan Ketelitian Mesin Perkakas, Bandung: ITB., 1999 